Sibiryakova I.G. (1996). Tematicheskoe strukturirovanie razgovornogo dialoga: Dis. ... kand. filol. nauk: 10.02 .01 [Thematic structuring of conversational dialogue: thesis of the doctor of Philology Sciences: 10.02.01]. Ekaterinburg, rukopis'.

Stepanenko V.A. (2017). Novye tendencii v metodike prepodavaniya RKI [New trends in the methodology of teaching Russian as a foreign language]. Tekst kul'tury i kul'tura teksta Materialy IV Mezhdunarodnogo pedagogicheskogo foruma, Sankt-Peterburg: Obshchestvo prepodavatelej russkogo yazyka i literatury, 736-741.

Harseeva D.O., Petrosyan O.B. (2018). Trudnosti audirovanie pri izuchenii RKI [Difficulties of listening in the study of Russian as a foreign language]. Vysshaya shkola: Problemy i perspektivy. Materialy 13-j Mezhdunarodnoj nauchno-metodicheskoj konferencii, 333-336.

Shalina I.V. (2011). Zhivaya rech' ural'skogo goroda: ustnye dialogi i epistolyarnye obrazcy: hrestomatiya [Live speech of the Ural city: oral dialogues and epistolary samples: anthology]. Ekaterinburg: Izd-vo Ural'skogo un-ta.

Shchukin A.N. (2010). Metodika prepodavaniya russkogo yazyka kak inostrannogo [Methods of teaching Russian as a foreign language] (2 nd ed.). Moskva: Vysshaya shkola.

For citation:

Pikuleva Yuliya (2019) AUDIOFILES WITH ORAL FAMILY COMMUNICATION IN THE PRACTICE OF TEACHING RUSSIAN AS A FOREIGN LANGUAGE // International Scientific-Pedagogical Organization of Philologists " WEST-EAST" (ISPOP). Scientific Journal WEST-EAST. Vol 2/1 N1 (October, 2019). p. 134-138. doi:

Для цитирования:

ПикУЛева Ю. Б. (2019) ЗАПИСИ УСТНОЙ СЕМЕЙНОЙ КОММУНИКАЦИИ В ПРАКТИКЕ ОБУЧЕНИЯ РУССКОМУ ЯЗЫКУ КАК ИНОСТРАННОМУ // Internationa 1Scientific-Pedagogical Organization of Philologists “ WEST-EAST” (ISPOP) . Scientific Journal WEST-EAST. Vol 1/1 N1 (October, 2019). C. 134-138. doi:

Information about the author: Pikuleva Yuliya Borisovna - PhD in Philology, Associate Professor, Department of Russian language, General linguistics and speech communication at Ural Federal University named after the first President of Russia B.N. Yeltsin,Yekaterinburg, Russia.

e-mail: pik@bk.ru

Сведения об авторе: Пикулева Юлия Борисовна - Кандидат филологических наук, доцент, кафедра русского языка. общего языкознания и речевой коммуникации, Уральский федеральный университет им. первого Президента России Б. Н. Ельцина, Екатеринбург, Россия.

e-mail: pik@bk.ru

Manuscript received: 05/23/2019 Accepted for publication: 09/20/2019

DOI:

\title{
INNOVATIVE PHRASEOLOGICAL DICTIONARIES AS A UNIVERSAL MEANS OF TRAINING, EDUCATION AND DEVELOPMENT OF PRIMARY SCHOOL PUPIL
}

\author{
Elena Rogaleva \\ DrHab (philology), Professor \\ Pskov State University \\ (Pskov, Russia) \\ e-mail: cambala2007@yandex.ru
}

\begin{abstract}
The article reveals modern approaches in the field of educational phraseography. The purpose of this article is to illustrate the concept of innovative phraseography for primary school using the materials of author's educational dictionaries. These dictionaries are built in the form of interactive cultural and cognitive hypertext, which has a high educational, cultural and educational potential. The article presents author's phraseographical method of discursive hypertext design, shows the tactics of etymological paraphrase in the system of text-forming techniques of innovative lexicography. The historical and etymological description of the phraseological unit is constructed using intellectual and developing technologies and involves the active participation of the pupils in the reconstruction of the etymological version: they observe, prove, generalize linguistic and cultural material, do the exercises and assignments related to different areas of knowledge. Innovative dictionaries, developed according to this author's concept, allow a primary school pupil to study a phraseological units in a complex way, as signs of language and culture.
\end{abstract}

Keywords: phraseography, educational dictionary, cultural and cognitive etymological hypertext, dictionary entry, primary school pupil 


\title{
ИННОВАЦИОННЫЕ ФРАЗЕОЛОГИЧЕСКИЕ СЛОВАРИ КАК УНИВЕРСАЛЬНОЕ СРЕДСТВО ОБУЧЕНИЯ, ВОСПИТАНИЯ И РАЗВИТИЯ МЛАДШИХ ШКОЛЬНИКОВ
}

\author{
Елена Ивановна Рогалёва \\ Доктор филологических наук, профессор \\ Псковский государственный университет \\ (Псков, Россия) \\ e-mail: cambala2007@yandex.ru
}

\begin{abstract}
Аннотация. В статье раскрываются современные подходы в области учебной фразеографии с учетом наметившейся тенденцией к повышению интереса у младших школьников к чтению литературы справочно-энциклопедического характера. Цель статьи - материалами учебных авторских словарей проиллюстрировать концепцию инновационных фразеологических словарей для начальной школы, представляющих собой интерактивный культурно-познавательный гипертекст, важнейшей характеристикой которого является наличие образовательного, культурологического, воспитывающего и развивающего потенциала. Это достигается за счет использования разработанного автором фразеографического метода дискурсивного гипертекстового конструирования с применением тактики этимологического парафразирования в системе текстоорганизующих приемов словарной репрезентации фразеологизмов младшему школьнику. В статье представлены материалы из фразеологического словаря в рассказах, где этимологическую версию с включением разнообразной информации, имеющей образовательно-развивающую и воспитательную направленность, раскрывают различные персонажи. Историко-этимологическая разработка фразеологизма строится с использованием интеллектуальноразвивающих технологий и предполагает активное участие ребенка в воссоздании этимологической версии: он наблюдает, доказывает, обобщает языковой и культурологический материал, выполняя сопутствующие задания, связанные с разными областями знаний. Инновационные словари, построенные по данной авторской концепции, позволяют младшему школьнику освоить фразеологизм комплексно, как знак языка и культуры.
\end{abstract}

Ключевые слова: фразеография, учебный словарь, культурно-познавательный этимологический гипертекст, словарная статья, младший школьник

ВВЕДЕНИЕ. Младшие школьники испытывают затруднения в понимании семантики фразеологизмов, осмыслении их внутренней формы, корректном употреблении в речи. Это обусловлено не столько возрастными особенностями развития интеллектуальной сферы детей 7-10 лет, но и недостаточным научно обоснованным лингвометодическим обеспечением процесса усвоения фразеологизмов, адекватного уровню развития ребенка.

Одним из эффективных средств обучения фразеологии является учебный словарь. Этим определяется актуальность нашего исследования, целью которого являлась разработка концепции учебного антропоориентированного фразеологического словаря - культурно-познавательного, развивающего и обучающего коммуникации. В свою очередь цель данной статьи - на авторских словарных материалах представить концепцию комплексной репрезентации фразеологизма посредством инновационной лексикографической технологии, направленной на обучение, воспитание и развитие младшего школьника.

ОБЗОР ЛИТЕРАТУРЫ. Как показал анализ литературы по проблеме нашего исследования, единичные исследования в сфере учебной фразеографии для адресата-ребенка затрагивают вопросы репрезентации фразеологизмов в словарях детской речи (Bestugina 2006), фразеографирования картины мира в текстах из детской художественной литературы (Petrenko 2008), выявления лингводидактических принципов конструирования фразеологического словаря для начальной школы (Basko 2016).

В качестве одного из перспективных направлений современной лексикографии выделяется разработка комплексных словарей, где языковые единицы получают подробную характеристику по многим параметрам, в результате чего создается многоаспектный лексикографический портрет слова (Bobunova 2009). К сожалению, большинство российских учебных фразеологических словарей (подробный анализ которых представлен в: (Rogaleva 2009) для начальной школы нельзя характеризовать как комплексные. Кроме семантизации фразеологизма они в некоторых случаях содержат лишь этимологическую справку.

Вместо с тем для формирования нашей фразеографической концепции важна тенденция (наметившаяся еще в 80-е годы прошлого столетия) к стиранию граней между разными типами словарей (в частности, между лингвистическими и энциклопедическими словарями) (Zaikovskaia 2011), за счет чего повышается информационная насыщенность словарной статьи, приобретающей комплексный характер, что особенно значимо для учебного словаря как средства обучения, воспитания и развития языковой личности.

При этом современные теоретики лексикографии отмечают, что словарная статья является полностью авторским творением (Rezunova, 2008), а ее наполнение обусловлено как направленностью и типом словаря, так и «духом и воздухом» той эпохи, в которую словарь задумывается и составляется (Ivanova 2010), что повышает его ценность как текста для познавательного чтения. В этой связи важно отметить, что последние исследования по изучению чтения в России показывают изменившееся к нему отношение детей по сравнению с 2000-2010 гг., когда наблюдался полный отказ от чтения. Сейчас многие дети младшего школьного возраста с интересом читают научно-познавательную литературу, отдавая предпочтение энциклопедическим источникам (Kolosova 2016).

С учетом этой тенденции в настоящее время в Экспериментальной лаборатории учебной лексикографии ПсковГУ создаются интерактивные фразеографические справочные пособия в бумажном формате для детей младшего школьного возраста (Rogaleva and Nikitina 2017), (Rogaleva and Nikitina 2018). Данные словари являются не только первой учебной репрезентацией русской фразеологии, гарантирующей успешное усвоение 
ребенком фразеологизма, но и становятся окном в мир русской культуры и истории, а также универсальным средством обучения, воспитания и развития младшего школьника.

МЕТОДЫ ИССЛЕДОВАНИЯ. В ходе исследования использовались приемы лингвокультурологического анализа, семантической идентификации и межъязыкового сопоставления фразеологизмов, методика структурно-семантического моделирования и описательный метод.

В целях реализации авторской концепции словарной репрезентации фразеологии адресату-ребенку был разработан лексикографический метод дискурсивного гипертекстового конструирования с использованием тактики этимологического парафразирования.

РЕЗУЛЬТАТЫ И ДИСКУССИЯ. Наша фразеографическая стратегия, направленная на формирование фразеологической компетенции младшего школьника, а также его общее интеллектуально-речевое развитие и воспитание, находит воплощение в комплексной репрезентации фразеологизма посредством инновационной лексикографической технологии (Rogaleva 2014).

Воспитательно-развивающий и обучающий потенциал фразеологического словаря обусловлен «культуроносностью» самих фразеологизмов и культурно значимыми сферами (Mokienko 1982), к которым они восходят:

I. Природа, животный и растительный мир: дрожать как осиновый лист, белены объелся и т.п.

II. Бытовая сфера: 1) реалии повседневной жизни прошлого - ни кола ни двора и т.п.; 2) единицы измерения - семи пядей во лбу; от горшка два вершка и т.п.; 3) денежные единицы - ломаного гроша не стоит и т.п.; 4) игры, развлечения, спорт - подложить свинью, бить в баклуши и т.п.; 5) народная кухня и пища проще пареной репь, тертый калач и т.п.;

III. Профессиональная сфера: доводить до белого каления, на одну колодку и т.п.

IV. История: коломенская верста, как Мамай прошел и т.п.

V. Духовная культура: 1) обряды, суеверия, верования - как в воду глядел и т.П.; 2) религиозные представления, связанные с христианством; церковнославянская книжность - к шапочному разбору, как сквозь землю провалился и т.п.; 3) русская письменность, книжное дело - от А до Я и т.п.

VI. Фольклор: тише воды ниже травы, по щучьему велению и т.п.

Согласно нашей концепции на базе научной версии происхождения фразеологизма посредством речевой тактики этимологического парафразирования конструируются вторичные культурно-познавательные тексты, интерпретирующие этимологическую версию применительно к условиям учебной коммуникации. Использование специальных текстоорганизующих приемов этимологической парафразы, позволяет познакомить младшего школьника с разноаспектной информацией культурно-познавательного характера, позволяющей не только сформировать у него мотив восприятия этимологии фразеологизма, но и создать широкое поле ассоциаций, на основе которых происходит метафорическое переосмысление прототипа. Таким образом, каждая сконструированная этимологическая парафраза реализует «образовательный, культурологический, воспитывающий и развивающий потенциал» учебного лексикографического текста (Voitik 2005).

Проиллюстрируем данные положения материалами словарных статей из фразеологического словаря в рассказах (Rogaleva and Nikitina 2018), где разноаспектная культурно-познавательная информация вплетается в сюжетную линию истории, которую излагают «авторитетные» рассказчики.

\section{«Мало каши ел»}

$<$..Эта фразеологическая история начинается в Санкт-Петербурге. Совсем недалеко от Дворцовой площади, на улице Миллионной нас ожидает наш сегодняшний рассказчик. Посмотри, вот он! (Рисунок одного Атланта Эрмитажа в Санкт-Петербурге)

- Впечатляющее зрелище, да? Ну, так я же - титан, могучий великан, один из героев древнегреческих мифов. Меня зовут Атлант.

Здесь, в Санкт-Петербурге, я работаю колонной, которая поддерживает балкон Нового Эрмитажа. Тяжело ли мне? Да что ты, ерунда! Это пушинка по сравнению с небом, которое я в наказание почти всю жизнь держал на своих плечах.

А тут я приятно отдыхаю. Ведь каждый, кто ко мне подходит, обязательно на моей ноге палец пощекочет. Это примета такая. Говорят, тогда твоё самое заветное желание сбудется. Вот мальчишки меня и щекочут - хотят стать такими же сильными, как я. Но это желание и загадывать не надо. Просто нужно есть больше каши. Каждый день. Как я в детстве. Каша даёт человеку силы и очень полезна для здоровья.

Конечно, всякое бывало. Иной раз и не доем ложку каши, чего не скажешь про моего приятеля Геркулеса (он же Геракл). После него тарелка всегда оставалась чистой. И вот результат. Мало того, что двенадцать подвигов совершил, так ещё и стал умнее меня. Даже сумел обхитрить в одном деле (эту историю я расскажу тебе в другой раз). А всё опять из-за каши.

Да, действительно, учёные доказали, что каша способствует развитию умственных способностей. И об этом хорошо знает повар Сгущёнкин, поэтому он со своей кашей уже тут как тут. Давай, поешь. Эту кашу в народе называют геркулесовой - она из овсяных хлопьев «Геркулес». Догадываешься, откуда такое название? (Рисунок тарелки с овсяной кашей).

Горячая? Ну, хорошо. Пусть остывает, а пока повар Сгущёнкин расскажет тебе о происхождения нашего фразеологизма.

Итак, выражение мало каши ел отражает значение каши как одного из основных видов питания на Руси. Каша - сытная и полезная еда. Ею часто кормят детей, ведь людям давно известно, что каша даёт силу и 
способствует росту ребенка. Ну, а тот, кто пока еще мало каши ел, остается слабым, не может справиться с серьезным, сложным делом - это и есть шутливый образ фразеологизма.

А сейчас вопрос из серии «Верю-не верю»:

- Веришь ли ты, что человек по сравнению с муравьём мало каши ел?

- И правильно делаешь, если веришь. Муравей перетаскивает камень в 50 раз больше своего веса. Если бы человек мог проявить такую «муравьиную» силу, то без труда перетащил бы на новое место одноэтажный дом...> (Rogaleva and Nikitina 2018).

Таким образом, помимо этимологии фразеологизма читатель получает культурологически значимую информацию об Эрмитаже в Санкт-Петербурге, о героях древнегреческой мифологии, традициях русской кухни, расширяет свой кругозор знаниями о представителях животного мира, получает полезные советы относительно рационального питания и укрепления здоровья.

В следующем примере воспитательный момент реализуется через репрезентацию семейных ценностей, страноведческие знания пополняются информацией о русских свадебных традициях, а привлечение персонажей-рассказчиков - представителей разных специальностей - позволяет ввести в словарный текст профориентационный компонент:

\section{«Отрезанный ломоть»}

$<\ldots$ У дверей в эту словарную статью остановился наш знакомый повар.

- Да Вы не стесняйтесь, повар Сгущёнкин, заходите!

- Да я не стесняюсь, просто не уверен, что эта моя история.

- Да как же не Ваша? Смотрите, в толковом словаре написано: «Ломоть -отрезанный для еды плоский кусок чего-нибудь: ломоть хлеба, ломоть сала, ломоть дыни». Конечно, Ваша!

- Ну, хорошо. Беру нож и отрезаю ломоть от батона (рисунок батона, а рядом отрезанного ломтя). И что? Как это связано с фразеологизмом отрезанньй ломоть? Ведь он обозначает человека, который отделился от семьи и не поддерживает с ней тесную связь. Я же говорю, что это не моя фразеологическая история. Позовите экскурсовода Раскопкина. Пусть лучше он разбирается. А тебе чем этот отрезанный ломоть намазать - вареньем или маслом? Обратно его не приставишь, а так оставлять нельзя. Заплесневеет.

- Это не розыгрыш? Вы, действительно, хотите, чтобы я, экскурсовод Раскопкин, рассказал о происхождении фразеологизма отрезанный ломоть? Я готов. Слушайте.

Повар Сгущёнкин оказался прав. Действительно, отрезанный ломоть к хлебу (к караваю) не приставишь. Это старинная русская пословица. Она и явилась источником нашего фразеологизма. Раньше на Руси так говорили про дочь, вышедшую замуж и ушедшую из родительского дома в семью мужа. Таковы уж были русские традиции.

В старину часто употребляли и такую поговорку : «Девочку в колыбельку , холсти́нку в коробейку ». Холсти́нка - это легкая льняная или хлопчатобумажная ткань. Коробейка - короб, большая плетеная коробка с крышкой. А общий смысл поговорки такой: если у вас родилась дочь, сразу же начитайте готовить ей приданое - имущество, с которым она уйдет из родительского дома в семью мужа. До середины XIX века приданое (постельное белье, скатерти, полотенца, одежду, посуду и т.п.) складывали в большие плетеные короба, позднее - в деревянные сундуки, украшенные резьбой, росписью, металлическими накладками. А от жениха девушке перед свадьбой приносили обязательный подарок - расшитые шёлком сапожки, чтобы она готовилась уйти из родного дома.

Позже отрезанным ломтем стали называть и сына, отделившегося от родителей. С особой горечью и сожалением так говорили о сыне престарелые родители, которым нужна была его помощь, ведь с каждым годом им становилось все труднее вести крестьянское хозяйство.

Ой, извини, пожалуйста. Я вынужден закончить экскурсию. Наш фразеологизм напомнил мне, что я давно не навещал своих родителей. А я ведь не какой-нибудь там отрезанный ломоть, а любящий, заботливый сын. Просто работа у меня увлекательная, иногда забываю обо всём на свете. Но ведь я благодаря своим маме и папе получил такое качественное образование и стал одним из лучших экскурсоводов в нашем городе. (Рисунок сын с подарками стоит. Мама и папа рядом).

А ты решил позвонить бабушке? Давно не виделись? Позвони, конечно. А еще лучше - навести ее сегодня же. Это самый лучший вывод из нашей фразеологической истории. А другие родные и близкие? Не забываешь ли ты поздравлять их с праздниками, навещать? Звонишь ли старым друзьям? (Рисунок экрана мобильного телефона на котором написано: «Позвони тем, кого ты стал забывать») ...> (Rogaleva and Nikitina, 2018).

ЗАКЛЮЧЕНИЕ. Таким образом, инновационные учебные словари, разработанные в рамках антропоцентрического подхода, комплексно репрезентирует фразеологизм посредством интерактивного культурно-познавательного гипертекста, который является новой формой словарного описания фразеологизмов. Образовательно-развивающие и воспитательные возможности этимологического словарного гипертекста определяются его полифункциональной природой, обусловленной богатейшим культурологическим и дидактическим потенциалом фразеологизма.

Каждая словарная статья отсылает читателя к текстам художественной литературы и русского фольклора, к тем или иным разделам математики, к темам учебных предметов начальной школы (окружающий мир, литературное чтение, иностранный язык, информатика и др.) с целью извлечения информации, необходимой для выстраивания этимологической версии или активизации рецептивных и продуктивных речевых навыков в сфере фразеологии. 
Таким образом, инновационные словари, построенные по данной авторской концепции, позволяют младшему школьнику освоить фразеологизм комплексно, как знак языка и культуры, а учителю, работающему с таким учебным словарем, помимо осуществления своих лингвометодических планов успешно решать воспитательные и образовательные задачи.

\section{LIST OF REFERENCES}

Basko, N.V. (2016). Leksikograficheskoe opisanie frazeologizmov v uchebnom frazeologicheskom slovare dlia uchashchikhsia nachal'noi shkoly [Lexicographical description of phraseological units in the educational phraseological dictionary for primary school students]. Nauka i shkola, (2), 76-83.

Bestugina, Iu. V. (2005). O leksikograficheskom opisanii frazeologicheskikh edinits $\mathrm{v}$ slovariakh detskoi rechi [About lexicographical description of phraseological units in dictionaries of children's speech]. V. Dal' v paradigme idei sovremennoi nauki: iazyk - slovesnost' - kul'tura - leksikografiia - frazeografiia. Ivanovo: Ivanovskii gosudarstvennyi universitet, 175-183.

Bobunova, M. A. (2009). Russkaia leksikografiia XXI veka [Russian lexicography of the XXI century]. Moskva.: Flinta: Nauka.

Voitik, N.V. (2005). Aktualizatsiia pedagogicheskogo potentsiala uchebnogo teksta (na primere obucheniia inostrannym iazykam v vuze) [Actualization of the pedagogical potential of the educational text (on the example of teaching foreign languages at the University)]. Obrazovanie i nauka. Izvestiia UrO RAO, (2), 33-39.

Zaikovskaia, I.A. (2011). Osobennosti realizatsii tekstovykh kategorii v pechatnom i elektronnom slovare [Features of implementation of text categories in the printed and electronic dictionary]. Izvestiia Rossiiskogo gosudarstvennogo pedagogicheskogo universiteta im. A. I. Gertsena, (130), 150-155.

Ivanova, E. P. (2010). Novye vozmozhnosti semantizatsii leksicheskoi edinitsy v mul'timediinom slovare [New capabilities of lexical units semantization of multimedia dictionary]. Uchenye zapiski Komsomol'skogo-na-Amure gosudarstvennogo tekhnicheskogo universiteta, (1-2), 49-53.

Kolosova, E.A. (2017). Potrebitel'skaia sotsializatsiia detei: podkhody i praktiki [Consumer socialization of children: approaches and practices]. Detstvo XXI veka v sotsiogumanitarnoi perspektive: novye teorii, iavleniia i poniatiia. Moskva: ROS, 139-158.

Mokienko, V. M. (1982). O tematiko-ideograficheskoi klassifikatsii frazeologizmov [About subject-ideographic classification of phraseological units]. Slovari i lingvostranovedenie. Moskva: Russkii iazyk, 1982, 108-121.

Petrenko, E. E. Frazeologicheskaia kartina mira v khudozhestvennykh tekstakh dlia mladshikh shkol'nikov [Phraseological picture of the world in literary texts for primary school pupils]. Cheliabinsk: ChGPU.

Rezunova, M. V. (2008). Slovarnaia stat'ia: tekst ili diskurs? [Dictionary entry: text or discourse?]. Izvestiia Volgogradskogo gosudarstvennogo pedagogicheskogo universiteta, (10), 47-49.

Rogaleva, E.I. \& Nikitina, T.G. (2017). Uma palata [He wasn't born yesterday]. Frazeologicheskii slovar' dlia detei Moskva: Izdatel'skii Dom Meshcheriakova.

Rogalyova E.I. \& Nikitina T.G. (2018). Sami s usami [We weren't born yesterday]. Vesyolyj frazeologicheskij slovar'. Moskva: Izdatel'skij Dom Meshheryakova.

Rogaleva, E.I. (2009). K kontseptsii interaktivnogo uchebnogo slovaria [On the concept of interactive educational dictionary]. Izvestiia Volgogradskogo gosudarstvennogo pedagogicheskogo universiteta. Seriia «Filologicheskie nauki», (7), 116-120.

Rogaleva E.I. (2014). Sovremennaya uchebnaya frazeografiya: teoriya i praktika [Modern educational phraseography: theory and practice]. Pskov: OOO LOGOS Plyus.

\section{For citation:}

Rogaleva Elena (2019) INNOVATIVE PHRASEOLOGICAL DICTIONARIES AS A UNIVERSAL MEANS OF TRAINING, EDUCATION AND DEVELOPMENT OF PRIMARY SCHOOL PUPIL // International Scientific-Pedagogical Organization of Philologists “WEST-EAST” (ISPOP). Scientific Journal WEST-EAST. Vol 2/1 N1 (October, 2019). p. 138-142. doi:

\section{Для цитирования:}

Рогалёва Е. И. (2019) ИННОВАЦИОННЫЕ ФРАЗЕОЛОГИЧЕСКИЕ СЛОВАРИ КАК УНИВЕРСАЛЬНОЕ СРЕДСТВО ОБУЧЕНИЯ, ВОСПИТАНИЯ И РАЗВИТИЯ МЛАДШИХ ШКОЛЬНИКОВ // Internationa IScientific-Pedagogical Organization of Philologists “WEST-EAST” (ISPOP) . Scientific Journal WEST-EAST. Vol 1/1 N1 (October, 2019). C. 138-142. doi:

Information about the author: Rogaleva Elena Ivanovna - DrHab (philology), Professor, Pskov State University (Pskov, Russia), e-mail: cambala2007@yandex.ru

Сведения об авторе: Рогалёва Елена Ивановна, доктор филологических наук, профессор, Псковский государственный университет (Псков, Россия), e-mail: cambala2007@yandex.ru 